\section{Genotypic and Environmental Effects on Paste Quality of Common Beans (Phaseolus vulgaris L.) Grown in Michigan}

\author{
Rie Sadohara and James D. Kelly \\ The Department of Plant, Soil and Microbial Sciences, Michigan State \\ University, 1066 Bogue Street, East Lansing, MI 48824
}

Karen A. Cichy

The Department of Plant, Soil and Microbial Sciences, Michigan State University, 1066 Bogue Street, East Lansing, MI 48824; and U.S. Department of Agriculture-Agricultural Research Service, Sugarbeet and Bean Research Unit, 1066 Bogue Street, East Lansing, MI 48824

Additional index words. bean paste, otebo, $\mathrm{G} \times \mathrm{E}$, Michigan, common bean, dry bean

\begin{abstract}
Common beans are recognized as a nutrient-dense food source that delivers numerous health benefits, but one of the barriers to increasing bean consumption is the limited number of common bean food products. Bean paste, made from bean seed and sugar, has the potential to diversify and expand the way beans are consumed. In this study, commercial white seeded otebo, navy, great northern, and white kidney bean cultivars and one colored cranberry bean were grown in two environments in Michigan and evaluated for bean paste qualities. Characteristics such as paste yield, color, flavor, and stickiness were evaluated on the bean paste. The genotype $\times$ environment effect was significant for many of the paste-making qualities and the color values of the unsweetened paste. 'Snowdon', the white kidney bean, had superior paste yield of unsweetened paste and whiteness of sweetened paste in both environments. All the white bean cultivars were comparable to Hime, the control otebo cultivar, in terms of low flavor intensity. 'Powderhorn', the great northern bean, had high stickiness of sweetened paste, which is preferable. The cranberry bean resulted in dark-colored paste with high flavor intensity. Seedcoat percentage and the ratio of $L^{*}$ and $C^{*}$ obtained via image analysis could be used as indicators for paste yield and whiteness score of the unsweetened paste, respectively. Overall, these results suggest that specific domestically grown white bean cultivars have potential for development as bean paste products, which would add a novelty to the processed dry bean applications in the United States.
\end{abstract}

Common beans (Phaseolus vulgaris L.) are a good source of protein, dietary fiber, vitamins, and minerals and offer numerous health benefits to consumers (Hayat et al., 2014; Messina, 2014). However, the annual per capita consumption of beans was only 5.8 pounds $(2.6 \mathrm{~kg}$ ) during 2011-15 (USDAERS, 2017). One of the reasons for low bean consumption is the limited number of product applications for which beans can be used (Desrochers and Brauer, 2001; Smith et al., 2016). Originating in Asia, bean paste is a

Received for publication 29 Oct. 2019. Accepted for publication 3 Mar. 2020.

Published online 14 April 2020.

We thank Filipe Couto Alves at CANR Biometry Group Statistical Consulting Center, Michigan State University, for advice on the statistical analyses.

K.A.C. is the corresponding author. E-mail: karen. cichy@usda.gov.

This is an open access article distributed under the CC BY-NC-ND license (https://creativecommons. org/licenses/by-nc-nd/4.0/). tion. High whiteness, stickiness, and smoothness are preferred for smooth, white paste. For paste flavor, lack of strong beaniness (bean-like flavor) or grassiness (green, grasslike flavor) is considered desirable. Paste yield is reported to be correlated with some seed and cooking quality traits (Kato, 2000), whereas other paste quality traits can only be measured by paste preparation and evaluation by a sensory panel. Because of the laborintensive nature of the evaluation process, predictive and high-throughput methods have been explored to accelerate the breeding process (Komiyama and Kato, 2004; Komiyama, 2013).

Several otebo market class cultivars were developed in Michigan to be exported for bean paste production (Kelly et al., 2009, 2016). For example, otebo bean cultivar Samurai was developed with taller upright architecture to suit direct machine harvest (Kelly et al., 2016). However, the potential of otebo beans and other white market classes for bean paste has not been evaluated due to the lack of screening tools to select for paste traits. Genotype $\times$ environment effects have been reported for bean paste quality traits (Komiyama and Kato, 2004), so these effects are also important considerations for bean growers across the state and the nation. The current study aimed to evaluate existing white bean cultivars for paste qualities, to investigate the effects of growing environments on the quality parameters, and to examine phenotypes useful for predicting paste qualities without the need for paste preparation.

\section{Materials and Methods}

Plant materials. Genotypes tested comprised five commercial white bean cultivars: Hime (otebo) (Miura et al., 1977), Samurai (otebo) (Kelly et al., 2016), Alpena (navy) (Kelly et al., 2015), Powderhorn (great northern) (Kelly et al., 2014), and Snowdon (white kidney) (Kelly et al., 2012), and a cranberry bean, CR1502-4 (Table 1). Hime was used as a control cultivar because it is an otebo bean cultivar used for commercial bean paste production (Kelly et al., 2009). The cranberry line was included because of its tendency to disintegrate during canning (unpublished data). The ability to break easily upon cooking is expected to be a suitable characteristic for paste making, which involves cooking beans until they start to disintegrate. The beans were grown as described by Kelly and Cichy (2012) at two experimental stations, Montcalm (MC, lat. $43^{\circ} 21^{\prime} 09.5^{\prime \prime} \mathrm{N}$, long. $85^{\circ} 10^{\prime} 36.2^{\prime \prime} \mathrm{W}$ ) and Saginaw Valley (SV, lat. $43^{\circ} 24^{\prime} 12.6^{\prime \prime} \mathrm{N}$, long. $83^{\circ} 41^{\prime} 58.8^{\prime \prime} \mathrm{W}$ ) in Michigan in 2017. The experiment was planted in a randomized complete block design with two field replications. At MC, each plot (replication) had two $6.1 \mathrm{~m}$-rows with $0.51 \mathrm{~m}$ row width, and genotypes were sown at the rate of $80 \mathrm{seeds} / \mathrm{row}$. The $4.6 \mathrm{~m}$-section of the two rows were harvested at maturity. At $\mathrm{SV}$, each plot had four 6.1-m rows with $0.51-\mathrm{m}$ row width. Genotypes were sown at 


\begin{tabular}{llccccc}
\hline Genotype & Hime & Samurai & Alpena & Powderhorn & Snowdon & CR1502-4 \\
\hline \hline \multirow{2}{*}{ Market class } & Otebo & Otebo & Navy & Great & White & \\
& & & & northern & Kidney & Cranberry
\end{tabular}

Seed color White White White $\quad$ Cream with

Type Cultivar Cultivar Cultivar Cultivar Cultivar Breeding line

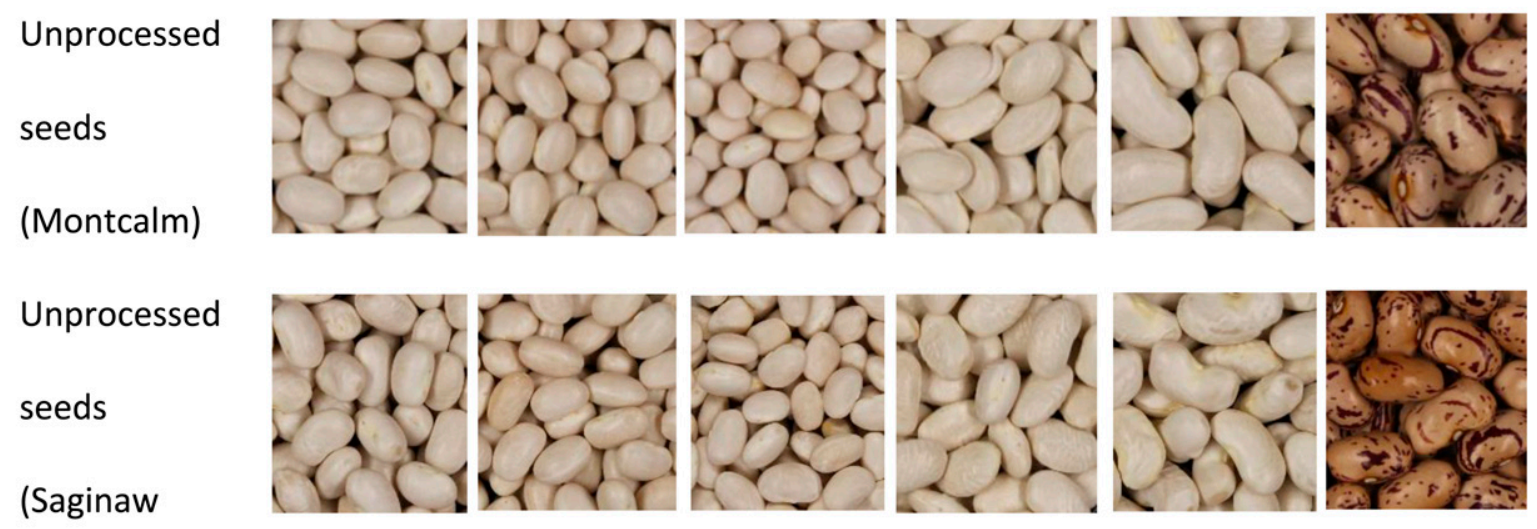

Valley)

the rate of 80 seeds/row in the center 2 rows, and a dark red kidney bean was sown in the outer two rows serving as borders. The 4.6-m section of the center two rows were harvested at maturity. Fertilizers were applied according to the local practices; $15-5-13+\mathrm{S}, \mathrm{Zn}$, $\mathrm{Mn}, \mathrm{Cu}$ prior planting at SV and 19-10-19 before planting and $46-0-0$ on day 27 at MC. Due to a low seed yield at SV, Hime was planted in two plots in each block, and the seeds from the two plots were combined. Throughout the growth period, a total of $137 \mathrm{~mm}$ of overhead irrigation was applied to supplement rainfall at $\mathrm{MC}$, but not at $\mathrm{SV}$. Beans were harvested at their full maturity with a Hege plot thresher. After harvest, beans were dried at room temperature, cleaned to remove chaff and large stones by using a seed cleaner (Clipper Office Tester, AT Ferrell Company Inc., Bluffton, IN), handcleaned to remove small stones and moldy or foreign seeds, and stored at a low temperature and low humidity chamber until the experiment was carried out. Before cooking, seed moisture was equilibrated in a cold storage room at $4{ }^{\circ} \mathrm{C}$ and $75 \%$ relative humidity and confirmed to be in the range of $10 \%$ to $14 \%$ before the samples were subjected to paste preparation.
Seed quality. The hundred-seed weight of each cultivar was determined as an average of three measurements for each field replication. Seed moisture was determined by drying 10 seeds in a convection oven at $105^{\circ} \mathrm{C}$ for $72 \mathrm{~h}$ with two replications. Seedcoat percentage was determined by soaking 15 seeds in distilled water for $16 \mathrm{~h}$, separating the coat from the cotyledon, and drying them at $105 \mathrm{C}^{\circ}$ for $24 \mathrm{~h}$. The coat percentage was determined as [coat weight, dry weight basis (dwb)] / (coat plus cotyledon weight, dwb). Seed moisture and coat percentage of each plot was determined as an average of two measurements. Soaked seed hardness was determined by using a TA.XTplus 100 with Exponent software ver. 6.1.11.0 (Stable Micro Systems Ltd., Godalming, UK). A sample of 20 seeds per field replication were soaked in distilled water for $16 \mathrm{~h}$, and each seed was punctured by a cylindrical $\varphi 2 \mathrm{~mm}$ probe, TA-52, with a compression rate of $70 \%$ with the pretest, test, and posttest speeds of 1,2 , and $2 \mathrm{~mm} / \mathrm{s}$, respectively. Peak positive force and peak positive area were recorded for each sample.

Bean paste preparation and cooking quality evaluation. For each field replication, paste was prepared with two technical repli- cations except CR1502-4 grown at SV, from which one paste sample was lost. Bean paste was prepared according to the method of Kato (2000) with modifications. Namely, $70 \mathrm{~g}$ of raw beans were soaked in distilled water for $16 \mathrm{~h}$ and drained to determine water uptake, calculated as (absorbed water weight) $/$ (raw bean weight) $\times 100$. Soaked beans were cooked in $2.5 \mathrm{~L}$ of distilled boiling water for $45 \mathrm{~min}$. The cooked beans were drained and weighed to determine the Weight Increase Rate by Boiling (WIRB), which was calculated as (boiled bean weight) / (raw bean weight, dwb). The drained cooked beans were then mashed with a wooden spatula for $8 \mathrm{~min}$ and passed through a $0.5-\mathrm{mm}$ sieve to remove the seedcoat. The cotyledon was washed with $800 \mathrm{~mL}$ distilled water, rested for $30 \mathrm{~min}$, and the supernatant was discarded. Washing with $500 \mathrm{~mL}$ distilled water followed by $10 \mathrm{~min}$ rest was repeated twice. The sediment was squeezed dry in a $50 \mathrm{~cm} \times 50 \mathrm{~cm}$ cheesecloth to remove excess moisture. The resultant unsweetened paste was weighed, and the moisture content was determined by drying $1 \mathrm{~g}$ of paste in a convection oven at $105 \mathrm{C}^{\circ}$ for $24 \mathrm{~h}$ in two replications. Paste yield was calculated as (unsweetened paste weight, dwb) / (raw bean weight, dwb). Unsweetened paste was 
sealed in plastic wrap and rested at $4 \mathrm{C}^{\circ}$ for $14 \mathrm{~h}$ before it was sweetened. Sweetened paste was prepared by heating $45 \mathrm{~g}$ of unsweetened paste with $45 \mathrm{~mL}$ of distilled water and $27.5 \mathrm{~g}$ of granulated sugar until the paste was $\times 1.3$ of the unsweetened paste weight $(58.5 \pm 0.1 \mathrm{~g})$. Sweetened paste was immediately sealed in plastic wrap and cooled to room temperature. The moisture content of sweetened paste was determined using the same methodology as unsweetened paste by using $2 \mathrm{~g}$ of sweetened paste samples. The color, stickiness, and whiteness were evaluated on the sweetened paste within $10 \mathrm{~h}$ of preparation.

Color. The color of unsweetened and sweetened paste was measured by taking a digital image of $42 \mathrm{~g}$ paste filled in a $\varphi 60$ $\mathrm{mm}$-glass petri dish and flattened by a spatula under the imaging conditions described by Mendoza et al. (2017) except that the shutter speed was set to $1 / 100 \mathrm{~s}$. Image $J$ software (Abramoff et al., 2004) was used to extract $\mathrm{L}^{*}, \mathrm{a}^{*}$, and $\mathrm{b}^{*}$ values (CIE International Commission on Illumination, 1978), from a $\varphi 56.4-\mathrm{mm}$ circle specified as a region of interest of each image. $\mathrm{L}^{*}$ is a luminance component value, ranging from complete black of 0 to complete white of 100 . Negative and positive values of $a^{*}$ and $b^{*}$ represent green-red and blue-yellow, respectively (Yam and Papadakis, 2004). Chroma ( $\left.\mathrm{C}^{*}\right)$ was determined as $C^{*}=\sqrt{a^{* 2}+b^{* 2}}$. The ratio $\mathrm{L} * / \mathrm{C}^{*}$ was calculated to assess the lightness of a paste sample in relation to its redness and yellowness.

Sensory evaluations. Sweetened and unsweetened samples were shaped into a $20 \times$ 30-mm rectangular shape with 4-mm thickness and were subjected to sensory evaluations. Four trained assessors evaluated eight samples per session. The assessors evaluated the whiteness, beaniness, vegetativeness, sweetness, and the total flavor intensity of unsweetened paste and the whiteness of sweetened paste on a 1 to 5 scale with 5 being the strongest. The samples' identity was not disclosed during the evaluation. The protocol was approved by the Michigan State University Biomedical, Health Sciences Institutional Review Board: IRB\# x16-763e Category: Exempt 6.

Stickiness. Stickiness was measured according to the method of Komiyama and Kato (2004) with slight modifications. Sweetened paste $(42 \mathrm{~g})$ in a $\varphi 60$ - $\mathrm{mm}$ petri dish described earlier was compressed by a texture analyzer, TA.XTplus 100 with Exponent software ver. 6.1.11.0, equipped with a platform (TA-90) and a $925.4-\mathrm{mm}$ cylindrical probe (TA-11) at a compression rate of $70 \%$ and with the pretest, test, and posttest speeds of 2, 2, and $1 \mathrm{~mm} / \mathrm{s}$, respectively. Stickiness was recorded as the negative area $\left(\mathrm{g} \cdot \mathrm{s}^{-1}\right)$ where the probe is pulled upward after compression.

Data analyses. The basic statistics of each trait were calculated by using the FSA package (Ogle et al., 2019) in the R platform (R Core Team, 2018). The scattered plot and the correlation coefficient of related traits were generated using the PerformanceAnalytics package (Peterson et al., 2019) in the R platform.

The PROC MIXED procedure of SAS software (ver. 9.4, SAS Institute, Cary, NC) was used to estimate the genotype $(\mathrm{G})$, environment $(\mathrm{E})$, and genotype $\times$ environment $(\mathrm{G} \times \mathrm{E})$ interaction effects and to compare the means of each sample within the environments. To analyze all the quality traits except the sensory attributes across the environments, a model of $Y_{i j k}=\mu+G_{i}+E_{j}+G_{i j}+B(E)_{j k}+$ $\varepsilon_{i j k}$ was used, where $Y_{i j k}$ is the trait value of the $i$ th genotype grown in the $k$ th block of the $j$ th environment, $\mu$ is the grand mean, $G_{i}$ is the fixed effect of the $i$ th genotype, $E_{j}$ is the fixed effect of the $j$ th environment, $\mathrm{GE}_{\mathrm{ij}}$ is the interaction term of the $i$ th genotype and the $j$ th environment, $\mathrm{B}(\mathrm{E})_{\mathrm{jk}}$ is the fixed effect of the $k$ th block nested in the $j$ th environment, and $\varepsilon_{\mathrm{ijk}}$ is the error term. To analyze the sensory attributes across the environments, a random effect of $l$ th subsamples $\left(\mathrm{S}_{1}\right)$, which was nested in block, was added to the model: $\mathrm{Y}_{\mathrm{ijkl}}=\mu+\mathrm{G}_{\mathrm{i}}+\mathrm{E}_{\mathrm{j}}+\mathrm{GE}_{\mathrm{ij}}+\mathrm{B}(\mathrm{E})_{\mathrm{jk}}+\mathrm{S}_{\mathrm{l}(\mathrm{jk})}+$ $\varepsilon_{\mathrm{ijkl}}$. To estimate and compare the means of genotypes within each environment, a model of $Y_{i k}=\mu+G_{i}+B_{k}+\varepsilon_{i k}$ was used for all the traits except the sensory attributes, for which $\mathrm{Y}_{\mathrm{ikl}}=\mu+\mathrm{G}_{\mathrm{i}}+\mathrm{B}_{\mathrm{k}}+\mathrm{S}_{\mathrm{l}(\mathrm{k})}+\varepsilon_{\mathrm{ikl}}$ was used. Normality of the residuals was evaluated by visual inspection of the quantile-quantile plots and histograms. The PROC GLIMMIX procedure was used to group the genotypic means within an environment. The PROC CORR procedure was used to estimate the correlation coefficient between related traits measured across the environments. All tests were carried out at $\alpha=0.05$ and mean comparison was done with Tukey adjustment.

\section{Results}

Seed quality. A graphic of the unprocessed dry seeds of each cultivar harvested from the two environments, $\mathrm{MC}$ and $\mathrm{SV}$, is shown in Table 1. The seeds of Hime, Snowdon, and CR1502-4 from SV were less plump and the seed surface was uneven compared with the seeds from MC. These differences suggest that the growing conditions were less favorable at SV than at $\mathrm{MC}$ for certain genotypes in 2017.

Table 2 shows the $\mathrm{G}, \mathrm{E}$, and $\mathrm{G} \times \mathrm{E}$ effects of the seed and paste qualities of each genotype grown in the two environments, $\mathrm{MC}$ and SV. G, E, and $\mathrm{G} \times \mathrm{E}$ effects were significant for all the seed qualities. Table 3 shows the means of the seed and paste qualities of each genotype grown in the two environments. All the genotypes had the same 100 seed weights in both environments except Snowdon and CR1502-4, which had lower seed weights at $\mathrm{SV}$. Genotypes grown at MC had lower seedcoat percentages than those grown at $\mathrm{SV}$ in general. There was a $\mathrm{G} \times \mathrm{E}$ effect on the seedcoat percentage (Table 2); 'Alpena', 'Snowdon', and CR1502-4 had lower seedcoat percentages than 'Hime' at MC, whereas 'Samurai' and 'Alpena' were lower than 'Hime' at SV (Table 3). For both the peak positive force and the positive area, MC samples had higher means than SV samples (Table 3). In addition, MC samples had a lower coefficient of variation (CV) than SV samples for the hardness measurements of soaked seeds (Table 2). 'Snowdon' and CR1502-4 at MC had low peak positive force of soaked seeds among the genotypes, but 'Snowdon' and 'Hime' had low peak positive force at SV (Table 3). The positive area measured the total force required to compress the soaked beans. 'Hime' had the highest positive area at $\mathrm{MC}$, but it was one of the lowest at SV. 'Alpena' and 'Snowdon' had lower values than other genotypes in both environments.

Cooking and paste-making qualities. $\mathrm{G}$, $\mathrm{E}$, and $\mathrm{G} \times \mathrm{E}$ effects were all significant for the paste-making qualities (Table 2). 'Powderhorn' and 'Snowdon' had a similar water uptake to 'Hime' in both environments. CR1502-4 had a comparable water uptake to 'Hime' at SV (Table 3). The two otebo cultivars, Hime and Samurai, had the highest WIRB at MC and SV, respectively. Differences in water uptake and WIRB among the samples were more pronounced at SV than MC (Table 2). 'Snowdon' had the highest paste yield, but other genotypes including 'Samurai' had a comparable paste yield to 'Hime' at MC. The five white-seeded cultivars had paste yields equivalent to that of 'Hime', whereas CR1502-4 was different from the other five cultivars at SV in terms of paste yield (Table 3 ). Figure 1 shows the correlation between the paste yield and the seed and cooking qualities. Paste yield was negatively correlated with the seedcoat percentage and positively correlated with soaked hardness (peak positive force and positive area) (Fig. 1). WIRB was not strongly correlated with paste yield (Fig. 1, $r=0.35$ ).

Whiteness and the color values of unsweetened paste. All the color values of unsweetened paste samples had G, E, and $\mathrm{G} \times \mathrm{E}$ effects except the E effect for the $\mathrm{a}^{*}$ value and the interaction effect for the $\mathrm{L}^{*}$ and $\mathrm{a}^{*}$ values (Table 2 ). The unsweetened paste made from all the genotypes had a similar L* value except CR1502-4 in both environments (Table 3). 'Snowdon' and 'Powderhorn' had lower a* values, whereas CR1502-4 had a high a* value in both environments. 'Alpena', 'Samurai', and CR1502-4 had low $b^{*}$ and $C^{*}$ values that were comparable to 'Hime', whereas 'Powderhorn' had high $\mathrm{b}^{*}$ and $\mathrm{C}^{*}$ values at MC. There was no difference among genotypes grown at SV for $\mathrm{b}^{*}$ and $\mathrm{C}^{*}$ values. 'Samurai' and 'Alpena' were the two highest for $\mathrm{L}^{*} / \mathrm{C}^{*}$ in both environments.

A sensory panel evaluated paste whiteness on a 1 to 5 scale with 5 being the whitest. There were $\mathrm{G}, \mathrm{E}$, and $\mathrm{G} \times \mathrm{E}$ effects for the whiteness of unsweetened paste (Table 2). 'Samurai', 'Alpena', and 'Snowdon' had similar whiteness to 'Hime', and 'Powderhorn' had a lower score at MC, whereas at SV, 'Powderhorn' was the whitest, and 'Hime' and 'Samurai' had relatively low whiteness scores (Table 3). In both environments, unsweetened paste made from CR1502-4 was by far the darkest. 
Table 2. The genotype (G), environment (E), and genotype $\times$ environment (G×E) effects on the traits measured and the basic statistics of each trait in two environments.

\begin{tabular}{|c|c|c|c|c|c|c|c|c|c|c|c|c|}
\hline & (unit) & G & $\mathrm{E}$ & $\mathrm{G} \times \mathrm{E}$ & Environment & $\mathrm{n}$ & Min. & Median & Max. & Mean & SD & $\mathrm{CV}(\%)$ \\
\hline \multicolumn{13}{|l|}{ Seed quality } \\
\hline \multirow[t]{2}{*}{100 seed weight } & (g) & $<0.0001$ & $<0.0001$ & $<0.0001$ & $\mathrm{MC}$ & 24 & 16.8 & 30.1 & 66.2 & 38.0 & 19.3 & 50.6 \\
\hline & & & & & SV & 24 & 17.0 & 27.6 & 52.9 & 33.0 & 12.7 & 38.5 \\
\hline \multirow[t]{2}{*}{ Seedcoat } & $(\%)$ & $<0.0001$ & $<0.0001$ & $<0.0001$ & $\mathrm{MC}$ & 24 & 6.3 & 7.3 & 8.0 & 7.2 & 0.4 & 5.6 \\
\hline & & & & & SV & 24 & 6.8 & 7.8 & 9.5 & 8.0 & 0.7 & 8.9 \\
\hline \multirow[t]{2}{*}{ Peak positive force ${ }^{z}$} & (g) & $<0.0001$ & $<0.0001$ & $<0.0001$ & $\mathrm{MC}$ & 240 & 1196 & 1704 & 2149 & 1710 & 159 & 9.3 \\
\hline & & & & & SV & 240 & 517 & 1407 & 2276 & 1400 & 326 & 23.3 \\
\hline \multirow[t]{2}{*}{ Positive area ${ }^{z}$} & $\left(\mathrm{~g} \cdot \mathrm{s}^{-1}\right)$ & $<0.0001$ & $<0.0001$ & $<0.0001$ & $\mathrm{MC}$ & 240 & 1076 & 2013 & 2854 & 2041 & 281 & 13.8 \\
\hline & & & & & SV & 240 & 590 & 1528 & 2406 & 1506 & 355 & 23.6 \\
\hline \multicolumn{13}{|l|}{ Paste-making quality } \\
\hline \multirow{2}{*}{ Water uptake } & $(\%)$ & $<0.0001$ & 0.001 & $<0.0001$ & $\mathrm{MC}$ & 24 & 98.0 & 105.6 & 113.6 & 105.8 & 5.0 & 4.7 \\
\hline & & & & & SV & 23 & 94.9 & 108.6 & 122.6 & 109.0 & 8.9 & 8.2 \\
\hline \multirow[t]{2}{*}{ WIRB } & (ratio) & $<0.0001$ & 0.001 & 0.001 & $\mathrm{MC}$ & 24 & 2.94 & 3.05 & 3.20 & 3.06 & 0.08 & 2.6 \\
\hline & & & & & SV & 23 & 2.65 & 2.94 & 3.36 & 2.98 & 0.19 & 6.2 \\
\hline \multirow[t]{2}{*}{ Paste yield } & (ratio) & $<0.0001$ & $<0.0001$ & $<0.0001$ & $\mathrm{MC}$ & 24 & 45.6 & 53.7 & 59.7 & 54.2 & 3.4 & 6.2 \\
\hline & & & & & SV & 23 & 28.1 & 46.7 & 51.1 & 44.8 & 5.8 & 13.0 \\
\hline \multicolumn{13}{|c|}{ Unsweetened paste quality } \\
\hline \multirow[t]{2}{*}{$\mathrm{L}^{*}$} & & $<0.0001$ & 0.002 & 0.073 & $\mathrm{MC}$ & 24 & 66.9 & 73.9 & 75.9 & 73.2 & 2.2 & 3.1 \\
\hline & & & & & SV & 23 & 63.7 & 73.4 & 75.9 & 72.5 & 2.9 & 4.0 \\
\hline \multirow[t]{2}{*}{$a^{*}$} & & $<0.0001$ & 0.072 & 0.059 & $\mathrm{MC}$ & 24 & 2.4 & 3.5 & 4.7 & 3.5 & 0.6 & 16.4 \\
\hline & & & & & SV & 23 & 2.3 & 3.5 & 5.2 & 3.6 & 0.8 & 21.5 \\
\hline \multirow[t]{2}{*}{$b^{*}$} & & 0.001 & $<0.0001$ & 0.017 & $\mathrm{MC}$ & 24 & 9.9 & 14.3 & 17.3 & 14.2 & 1.7 & 12.2 \\
\hline & & & & & SV & 23 & 13.5 & 16.2 & 18.0 & 16.1 & 1.4 & 8.5 \\
\hline \multirow[t]{2}{*}{$\mathrm{C}^{*}$} & & 0.003 & $<0.0001$ & 0.011 & $\mathrm{MC}$ & 24 & 10.9 & 14.7 & 17.7 & 14.6 & 1.6 & 10.8 \\
\hline & & & & & SV & 23 & 14.2 & 16.5 & 18.4 & 16.5 & 1.3 & 8.2 \\
\hline \multirow[t]{2}{*}{$\mathrm{L}^{*} / \mathrm{C}^{*}$} & & 0.011 & $<0.0001$ & 0.011 & $\mathrm{MC}$ & 24 & 4.2 & 5.1 & 6.1 & 5.1 & 0.5 & 9.8 \\
\hline & & & & & SV & 23 & 3.6 & 4.4 & 5.2 & 4.4 & 0.5 & 10.5 \\
\hline \multirow[t]{2}{*}{ Whiteness } & $(\text { score })^{y}$ & $<0.0001$ & 0.015 & $<0.0001$ & $\mathrm{MC}$ & 96 & 1.0 & 4.0 & 5.0 & 4.1 & 1.2 & 29.7 \\
\hline & & & & & SV & 92 & 1.0 & 4.0 & 5.0 & 3.8 & 1.1 & 29.0 \\
\hline Beaniness & (score) & 0.003 & 0.139 & 0.186 & $\mathrm{MC}$ & 96 & 1.0 & 2.0 & 5.0 & 2.3 & 1.3 & 55.8 \\
\hline & & & & & SV & 92 & 1.0 & 2.0 & 5.0 & 1.9 & 1.0 & 53.0 \\
\hline Vegetativeness & (score) & 0.904 & 0.645 & 0.303 & $\mathrm{MC}$ & 96 & 1.0 & 2.0 & 5.0 & 1.9 & 1.0 & 51.8 \\
\hline & & & & & SV & 92 & 1.0 & 2.0 & 5.0 & 2.0 & 1.0 & 51.3 \\
\hline Sweetness & (score) & 0.134 & 0.725 & 0.625 & $\mathrm{MC}$ & 96 & 1.0 & 1.0 & 3.0 & 1.2 & 0.4 & 35.6 \\
\hline & & & & & SV & 92 & 1.0 & 1.0 & 5.0 & 1.3 & 0.7 & 57.4 \\
\hline Total flavor intensity & (score) & 0.006 & 0.878 & 0.048 & $\mathrm{MC}$ & 96 & 1.0 & 2.0 & 5.0 & 2.3 & 1.1 & 48.3 \\
\hline & & & & & SV & 92 & 1.0 & 2.0 & 5.0 & 2.3 & 1.0 & 45.3 \\
\hline Sweetened paste qualit & & & & & & & & & & & & \\
\hline $\mathrm{L}^{*}$ & & $<0.0001$ & 0.128 & 0.748 & $\mathrm{MC}$ & 24 & 28.8 & 54.1 & 69.3 & 53.1 & 11.2 & 21.1 \\
\hline & & & & & SV & 23 & 30.2 & 60.3 & 69.3 & 56.9 & 10.3 & 18.2 \\
\hline$a^{*}$ & & $<0.0001$ & 0.045 & 0.014 & $\mathrm{MC}$ & 24 & 3.6 & 5.7 & 7.1 & 5.6 & 1.0 & 17.2 \\
\hline & & & & & SV & 23 & 3.7 & 5.9 & 7.6 & 6.0 & 1.0 & 16.1 \\
\hline$b^{*}$ & & $<0.0001$ & $<0.0001$ & 0.526 & $\mathrm{MC}$ & 24 & 9.3 & 23.0 & 28.5 & 21.9 & 4.9 & 22.4 \\
\hline & & & & & SV & 23 & 11.6 & 25.5 & 29.3 & 24.6 & 4.5 & 18.1 \\
\hline $\mathrm{C}^{*}$ & & $<0.0001$ & $<0.0001$ & 0.358 & $\mathrm{MC}$ & 24 & 11.1 & 23.7 & 29.3 & 22.6 & 4.6 & 20.5 \\
\hline & & & & & SV & 23 & 13.2 & 26.1 & 30.2 & 25.4 & 4.2 & 16.5 \\
\hline $\mathrm{L}^{*} / \mathrm{C}^{*}$ & & 0.010 & 0.152 & 0.720 & $\mathrm{MC}$ & 24 & 1.8 & 2.3 & 3.5 & 2.4 & 0.4 & 16.6 \\
\hline & & & & & SV & 23 & 1.8 & 2.3 & 2.7 & 2.2 & 0.3 & 11.6 \\
\hline Whiteness & (score) & $<0.0001$ & 0.988 & 0.011 & $\mathrm{MC}$ & 96 & 1.0 & 4.0 & 5.0 & 3.5 & 1.4 & 41.3 \\
\hline & & & & & SV & 92 & 1.0 & 4.0 & 5.0 & 3.6 & 1.2 & 32.4 \\
\hline Stickiness & $\left(\mathrm{g} \cdot \mathrm{s}^{-1}\right)$ & $<0.0001$ & 0.065 & 0.079 & $\mathrm{MC}$ & 24 & 2979 & 4204 & 6910 & 4378 & 1123 & 25.7 \\
\hline & & & & & SV & 23 & 2253 & 4000 & 5438 & 4015 & 843 & 21.0 \\
\hline
\end{tabular}

$\mathrm{MC}=$ Montcalm; SV = Saginaw Valley; WIRB = weight increase rate by boiling.

${ }^{\mathrm{z}}$ Peak positive force and positive area: Soaked hardness measurements.

${ }^{\mathrm{y}}$ Score: $1-5$ scale, with 5 being the strongest.

Figure $2 \mathrm{~A}$ shows the correlation coefficients and the scatter plots between the whiteness score and the color values obtained by the image analysis of unsweetened paste. When all the 47 paste samples were used, the whiteness of unsweetened paste was strongly correlated with $\mathrm{L}^{*}$ and $\mathrm{a}^{*}$ values, but it was due to CR1502-4 which had a darker paste with low $\mathrm{L}^{*}$ and high $\mathrm{a}^{*}$ values, compared with the other genotypes. Therefore, the correlation between the whiteness score and the color values were examined after the seven CR1502-4 paste samples were removed (Fig. 2B, $n=40$ ). The whiteness score had a positive correlation with $\mathrm{L}^{*}$ and $\mathrm{L}^{*} / \mathrm{C}^{*}$ and a negative correlation with $a^{*}, b^{*}$, and $C^{*}$ as expected. The $L^{*} / C^{*}$ had a higher correlation coefficient than $\mathrm{L}^{*}$ with the whiteness score.

Whiteness and the color values of sweetened paste. The genotype effects were significant for all the color values of sweetened paste, but the environmental effects were significant only for $\mathrm{a}^{*}, \mathrm{~b}^{*}$, and $\mathrm{C}^{*}$ values (Table 2 ). $\mathrm{G} \times \mathrm{E}$ effects were significant only for the $\mathrm{a}^{*}$ value. Similar to the unsweetened paste, all white-seeded genotypes produced sweetened paste with similar $\mathrm{L}^{*}$ values, whereas CR1502-4 had a low L* value. 'Hime', 'Samurai', and 'Alpena' had similar a*, b*, $\mathrm{C}^{*}$, and $\mathrm{L}^{*} / \mathrm{C}^{*}$ values (Table 3 ). 'Snowdon' had low mean values of $\mathrm{a}^{*}$, and 'Powderhorn' had high $b^{*}$ values in both environments. 'Snowdon' had the highest $\mathrm{L}^{*} / \mathrm{C}^{*}$ value at $\mathrm{MC}$, whereas $\mathrm{L}^{*} / \mathrm{C}^{*}$ was not different among the genotypes at SV.

The whiteness scores evaluated by assessors had $\mathrm{G}$ and $\mathrm{G} \times \mathrm{E}$ effects (Table 2). All the sweetened paste made from the white-seeded genotypes had a similar score as 'Hime', but 'Snowdon' was the whitest, producing its highest $\mathrm{L}^{*} / \mathrm{C}^{*}$ value at MC (Table 3). 'Powderhorn' and 'Snowdon' had higher whiteness scores than 'Hime', 'Samurai', and 'Alpena' at SV. CR1502-4 was the darkest for the whiteness evaluation in both environments, as was also observed with the unsweetened paste evaluation. 
Table 3. Mean values for agronomic and paste quality traits of six bean genotypes grown in the two environments in Michigan.

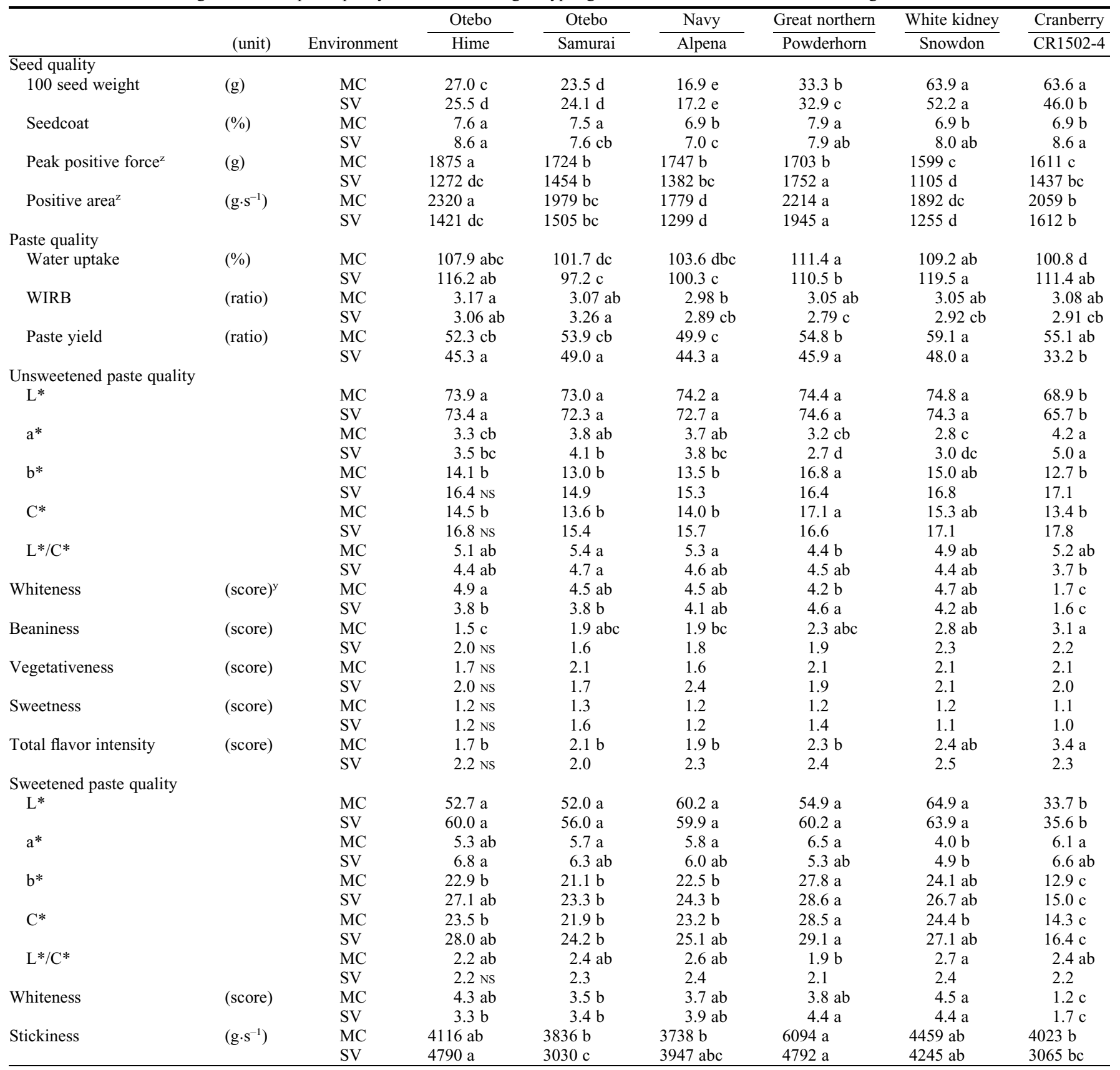

Means with the same letter in the same row are not different $(\alpha=0.05)$. MC $=$ Montcalm; SV = Saginaw Valley; WIRB = weight increase rate by boiling; $\mathrm{NS}=$ not significant. ${ }^{z}$ Peak positive force and positive area: hardness measurements of soaked seeds.

${ }^{\mathrm{y}}$ Score: $1-5$ scale with 5 being the strongest.

Figure $3 \mathrm{~A}$ shows the correlation coefficients and the scatter plots between the whiteness score and the color values obtained by the image analysis of sweetened paste made from all the six genotypes $(\mathrm{n}=$ 47). Similar to unsweetened paste, the $L^{*}$, $a^{*}, b^{*}$, and $C^{*}$ values were correlated with the whiteness score, but it was due to the paste made from CR1502-4 that had lower $L^{*}$ and $b^{*}$ values than other genotypes; therefore, the data points of CR1502-4 from both environments were removed (Fig. 3A and B, $\mathrm{n}=40$ ). When CR1502-4 was removed, the whiteness score was not strongly correlated with any color values or the composite values (Fig. 3B).
Flavor of unsweetened paste. The beaniness, vegetativeness, sweetness, and the total flavor intensity of the unsweetened paste were evaluated on a 1 to 5 scale. The CV was high for these flavor attributes in both environments compared with other traits (Table 2). There was G effect on the beaniness and the total flavor intensity and GXE effects on the total flavor intensity. There were no G, E, or G×E effects on vegetativeness and sweetness. The genotypes were different in beaniness and in the total flavor intensity only at MC (Table 3 ). 'Samurai', 'Alpena', and 'Powderhorn' had similar beaniness and total flavor intensity scores as 'Hime', whereas 'Snowdon' and
CR1502-4 had greater scores than other cultivars at MC. All the genotypes had similar and low scores for sweetness in both environments.

Stickiness of sweetened paste. There was a genotypic effect on the stickiness of sweetened paste, but the environment and the interaction effects were not significant (Table 2). All samples at MC had similar values to 'Hime'; and 'Alpena', 'Snowdon', and 'Powderhorn' had a comparable stickiness to 'Hime' at SV. 'Powderhorn' had the highest stickiness in both environments. The genotypes could be divided into two groups based on their stickiness values: 'Hime', 'Powderhorn', and 'Snowdon' with high stickiness and 


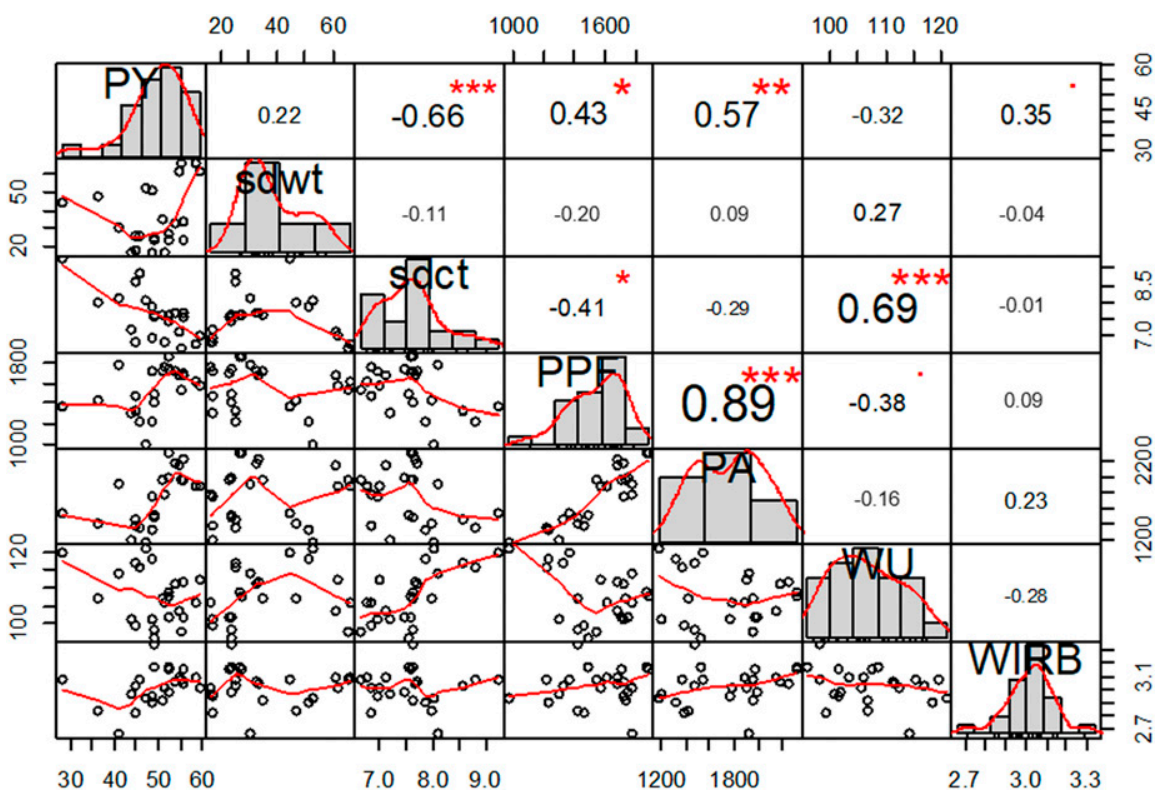

Fig. 1. The correlation coefficients and scatter plots of paste-making and cooking quality traits with data points from the two environments combined. $\mathrm{PY}=$ paste yield; $\mathrm{sdwt}=100$ seed-weight; sdct $=$ seedcoat percentage $\mathrm{PPF}=$ peak positive force of soaked seeds; $\mathrm{PA}=$ positive area of soaked seeds; $\mathrm{WU}=$ water uptake; WIRB $=$ weight increase rate by boiling. $* * * P<0.001, * * P<0.01, * P<0.05$.

'Samurai', 'Alpena', and CR1502-4 with low stickiness.

\section{Discussion}

Cooking- and paste-making qualities in relation to seed quality. Bean paste has the potential to be a novel end-use of dry beans, which would lead to increased bean consumption. Therefore, this experiment tested the bean paste qualities of existing cultivars and a breeding line developed in Michigan compared with 'Hime', the industry standard developed in Japan. The cultivars were grown in two contrasting environments in Michigan, one irrigated (MC), the other rainfed $(\mathrm{SV})$.

Paste yield, the efficiency of producing unsweetened paste from raw seeds, is an important characteristic for bean paste producers. 'Snowdon' had high paste yield at $\mathrm{MC}$ and a comparable yield to 'Hime' at SV. On the basis of data from these two environments, the suitability of 'Snowdon' for paste production is promising. The paste yield of CR1502-4 was environment dependent; it had high paste yield at MC and low paste yield at SV. Other genotypes had a comparable paste yield to 'Hime' in both environments. It is noteworthy that the $\mathrm{CV}$ for paste yield was higher at SV than MC, suggesting that some genotypes produce less uniform paste when grown at SV. In addition, all the genotypes had less paste yield at SV than $\mathrm{MC}$. The irrigation at MC may have produced seeds that are easier to cook and to separate the seedcoat during paste preparation. Despite the low paste yield, some genotypes from SV had a higher water uptake, presumably because some of the genotypes from this environment had cracked and/or peeled seeds during soaking, which made further imbibi- tion easier. However, the high water uptake of SV seeds did not lead to high paste yield; on the contrary, as the low WIRB indicated, the seeds were less cooked, resulting in less separation of cotyledon cells and low paste yield. 'Samurai' was an exception as it had a WIRB as high as 'Hime' at SV (Table 3). 'Samurai' was bred as an otebo bean, and its seed characteristics derived from the otebo pedigree may have resulted in high water uptake during cooking, a characteristic preferable for bean paste production. A related study of a black and pinto bean indicated that the starch granules of the two cultivars grown under rainfed conditions had a high ability to absorb water and swell but also were more susceptible to shear and granule rupture than those grown under irrigation (Ovando-Martínez et al., 2011). Although the current study did not include black or pinto beans, the environment and water regime likely influenced the cooking quality of the beans tested.

A previous study reported a positive correlation between WIRB and paste yield (Kato, 2000). The low correlation between WIRB and paste yield in this study (Fig. 1) was deemed to be due to one of the CR1502-4 paste samples grown at SV that had an extremely low paste yield (28.1). This was a moderate outlier ( $>1.5$ times of the interquartile range for this environment), and the correlation was higher $(r=0.52, P=0.010)$ when this data point was removed. Thus, WIRB could be a useful indicator of paste yield when genotypes that had extremely low paste yield are excluded from the analysis. The seedcoat percentage was negatively correlated with paste yield, as expected, and could be another indicator of paste yield (Fig. 1). From a practical point of view, the seedcoat percentage would be a better indicator of paste yield than WIRB because it is easier to measure and does not involve the labor-intensive cooking process. However, very small beans such as navy may be outside the range of prediction because 'Alpena' did not have a high paste yield at MC despite its low seedcoat percentage (Table 3). Navy beans in the United States have long been bred for high tolerance to seedcoat splitting during canning operation, and the seedcoat of the tolerant navy lines tightly adhere to the cotyledon (Dorrell and Adams, 1969). This may explain why the seedcoat removal after cooking of 'Alpena' was not as efficient during the paste preparation.

Whiteness and color values of unsweetened and sweetened paste. The L* (lightness), a* (redness), and $\mathrm{b}^{*}$ (yellowness) values indicated that the unsweetened paste made from 'Hime', 'Samurai', and 'Alpena' tend to be more red, whereas the unsweetened paste made from 'Powderhorn' and 'Snowdon' tend to be more yellow than red (Table 3 ). This trend was mostly the same with the sweetened paste except with 'Powderhorn' grown at MC, which had the highest $a^{*}$ value. CR1502-4 resulted in a very dark-colored paste unlike the other white genotypes. Cranberry beans have red pigments similar to Adzuki beans used for red paste; however, the color values of unsweetened paste of CR1502-4 were different from those typically found with Adzuki unsweetened paste (L*: 40, a*: 6, b*: 6) (Tazawa et al., 2015). There is no precedence of making paste from cranberry beans, so this result has provided new information on the end-use characteristic of this market class.

The whiteness scores of sweetened paste made from the white-seeded bean cultivars indicated that all those cultivars are likely to produce similar sweetened paste to 'Hime' (Table 3). The high whiteness score of sweetened paste made from 'Snowdon' in both environments indicated that this cultivar may withstand darkening during the sweetening process. High whiteness of sweetened paste is highly valued because it directly affects the confectionery product quality for which bean paste is used. 'Hime' and 'Powderhorn' produced paste with different whiteness scores depending on the environment, indicating that the growing environment plays an important role on paste color for some genotypes.

Prediction of whiteness using color values. Considering that all the unsweetened paste had similar L* values except CR1502-4, the $\mathrm{L}^{*}$ value alone is not sufficient to capture the overall impression on the unsweetened paste color evaluated by the sensory panel (Table 3 ). Therefore, composite values such as $\mathrm{C}^{*}$ and $\mathrm{L} * / \mathrm{C}^{*}$ were examined. $\mathrm{C}^{*}$ and $\mathrm{L}^{*} / \mathrm{C}^{*}$ were influenced largely by $\mathrm{b}^{*}$ because the paste samples had larger $b^{*}$ values than $a^{*}$ (Table 2). The $\mathrm{L}^{*} / \mathrm{C}^{*}$ values could be used to predict whiteness scores given by a sensory panel on unsweetened paste made from white beans. Color values such as $\mathrm{L}^{*}, \mathrm{a}^{*}$, and $b^{*}$, measured using colorimeters, have been used for evaluating bean paste color (Okuyama et al., 2008; Shinada et al., 1994), but no study has examined machine vision and image analysis technology for this 


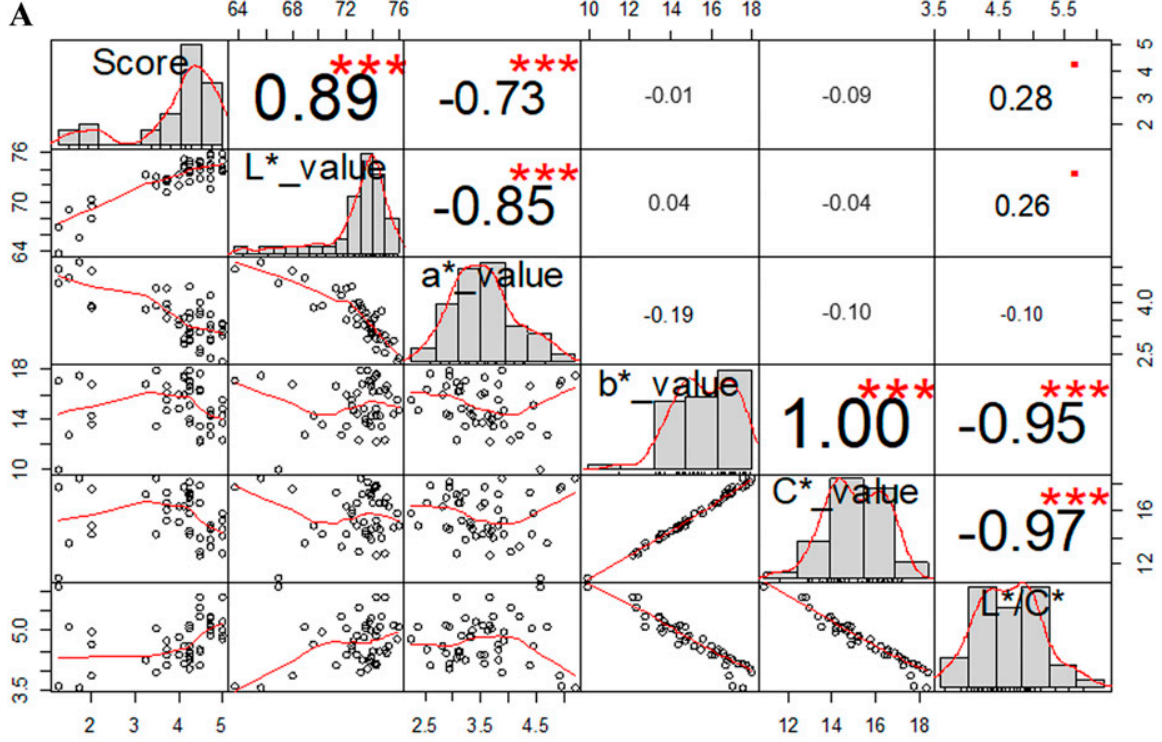

B

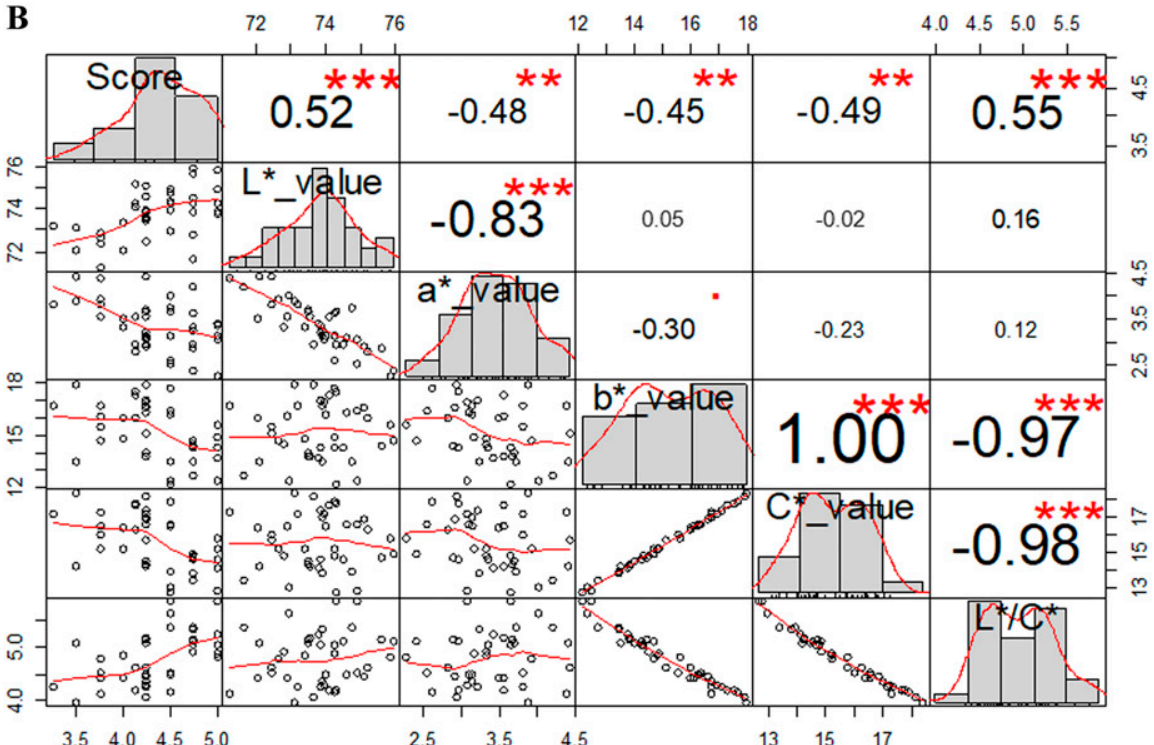

Fig. 2. The correlation coefficients and scatter plots of whiteness scores evaluated by assessors and color values of unsweetened paste. Score: whiteness score rated by assessors. $\mathrm{L}^{*}, \mathrm{a}^{*}, \mathrm{~b}^{*}$ : color values obtained by image analysis; $C^{*}$ : chroma; $L^{*} / C^{*}$ : the ratio of $L^{*}$ and $C^{*}$. (A) All data points $(n=47)$ used; (B) data points except CR1502-4 $(\mathrm{n}=40) .{ }^{* * *} P<0.001,{ }^{* *} P<0.01,{ }^{*} P<0.05$.

purpose. Computer vision is widely used for evaluating the color of food products at a high resolution (Wu and Sun, 2013). This method could be used for an objective and efficient screening of breeding lines for white paste color without the need for training assessors.

The $\mathrm{L}^{*} / \mathrm{C}^{*}$ values of sweetened paste differentiated genotypes grown at $\mathrm{MC}$ but not at SV despite the difference between them detected by the assessors (Table 3). Still, 'Snowdon' had a high $\mathrm{L}^{*} / \mathrm{C}^{*}$ and high whiteness score at $\mathrm{MC}$; thus, $\mathrm{L}^{*} / \mathrm{C}^{*}$ may be useful in identifying outstandingly white sweetened paste. $\mathrm{L}^{*} / \mathrm{C}^{*}$ or other color values were not strongly correlated with the whiteness score of the five white genotypes (Fig. 3B). One possible reason for this is that $\mathrm{L}^{*}, \mathrm{~b}^{*}, \mathrm{C}^{*}$, and $\mathrm{L}^{*} / \mathrm{C}^{*}$ of sweetened paste had higher $\mathrm{CV}$ than those of unsweetened paste (Table 2), indicating that within-sample variability increased when paste was sweetened. This is probably because the sweetening process involves manual stirring (Shiota and Miyata, 1976) and is difficult to perform consistently. To rank genotypes according to the whiteness score of sweetened paste, a trained panel of assessors may still be necessary, but it is a costly way to evaluate a large number of samples. The whiteness score of unsweetened paste was positively correlated with that of sweetened paste made from the white genotypes ( $r=0.45, P=0.0033$ ); thus, an economical approach might be to evaluate unsweetened paste by comparing the $\mathrm{L}^{*} / \mathrm{C}^{*}$ values first obtained by image analysis, thereby indirectly selecting for high whiteness of sweetened paste. Later in the selection, a sensory panel could evaluate sweetened paste samples made from a smaller number of elite lines.

Flavor of unsweetened paste. None of the flavor attributes had significant E (environment) effects, indicating that the flavor attributes are not influenced by environment. Nonsignificant environmental effects on the flavor were consistent with a previous study that compared the aroma and flavor of six solid red, red-striped, or dark-striped beans (Mkanda et al., 2007). The high CV of the flavor attributes was due to the high variability among the assessors. Unlike technical replications of other trait measurements, higher variability in sensory evaluation is expected because the assessors are individuals with varying sensitivity to different flavor attributes. However, the way assessors differentiated the samples aligned with the expected results such as the low flavor intensity of 'Hime', the control cultivar, and the high flavor intensity of nonwhite, cranberry genotype at MC (Table 3). The similar and low flavor intensity among the white beans suggested that any white-seeded genotypes are comparable to 'Hime' in terms of flavor despite 'Snowdon' being higher in beaniness at MC.

The unsweetened paste made from CR1502-4 had the highest beany flavor compared with other white beans at MC. This finding was in line with a previous study where two maroon-mottled and two solid beige beans from Europe tended to have stronger flavor than solid white beans when tasted as whole boiled beans (Rivera et al., 2013). The authors also reported that the flavor intensity was negatively correlated with the percentage of white color on the seeds in their collection, which consisted of 20 accessions of various colors. It may explain the stronger flavor detected in the cranberry genotype in this study on the assumption that the flavor characteristics of whole beans reflect those of unsweetened paste. All genotypes had similar and low vegetativeness and sweetness in both environments, indicating that those attributes of bean paste are too subtle and indistinguishable between the genotypes. The similar scores of sensory attributes among the paste samples at SV may indicate that beans would produce paste with a more similar flavor grown in this environment. However, considering the high $\mathrm{CV}$ of the soaked hardness and paste-making qualities of the genotypes at SV, it is also possible that the paste samples had high within-genotype variability that led to reduced statistical power to detect differences between the genotypes. Further research is necessary to test this hypothesis.

Stickiness of sweetened paste. The significant $G$ effect and the insignificant $E$ and $\mathrm{G} \times \mathrm{E}$ effects indicated that genotype is an important factor for this trait. The high stickiness of 'Powderhorn' in both environments is a favorable characteristic for bean paste made without the seedcoat Stickiness is evaluated by preparing paste, 


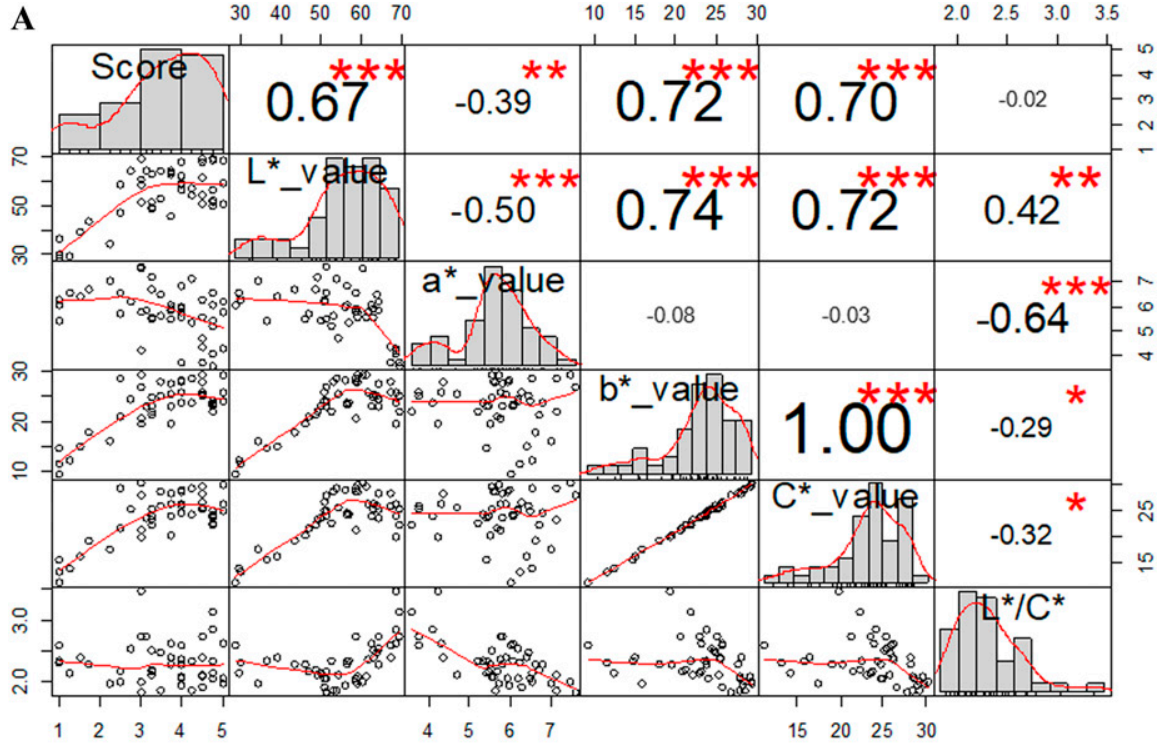

B

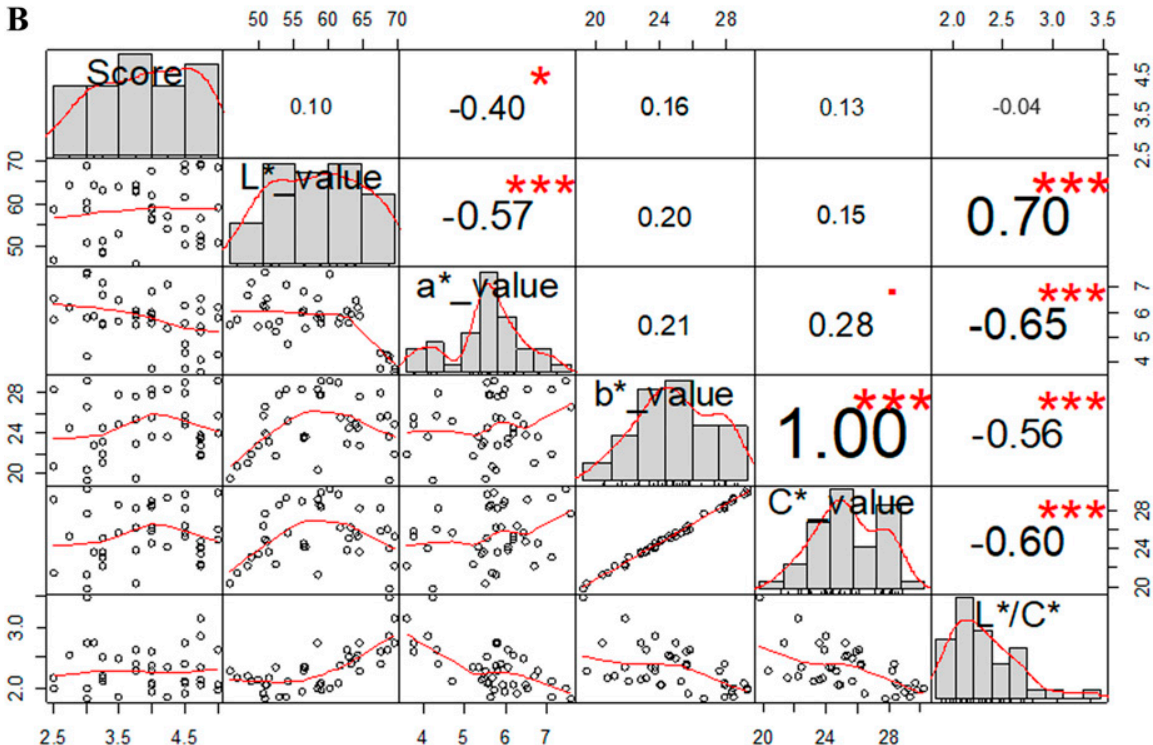

Fig. 3. The correlation coefficients and scatter plots of whiteness scores evaluated by assessors and color values of sweetened paste. Score: whiteness score rated by assessors. $\mathrm{L}^{*}, \mathrm{a}^{*}, \mathrm{~b}^{*}$ : color values obtained by image analysis; $\mathrm{C}^{*}$ : chroma; $\mathrm{L}^{*} \mathrm{C}^{*}$ : the ratio of $\mathrm{L}^{*}$ and $\mathrm{C}^{*}$. (A) All data points $(\mathrm{n}=47)$ used; $(\mathbf{B})$ data points except CR1502-4 $(\mathrm{n}=40) .{ }^{* * *} P<0.001,{ }^{*} P<0.01,{ }^{*} P<0.05$.

and no phenotype was suggested as a predictor of stickiness. However, the protein content of sweetened paste was correlated with stickiness for some otebo cultivars and breeding lines (Komiyama and Kato, 2004). As a future study, the protein content of sweetened and unsweetened paste can be measured to facilitate the understanding of the genotypic differences in paste stickiness. The moisture contents of the sweetened paste samples were not correlated with stickiness $(P=0.75)$; thus, it did not explain the genotypic differences.

\section{Conclusions}

Bean paste could be a novel use of dry beans, and this study revealed the potential of Michigan-grown white-seeded beans for paste production. All the white cultivars

'Himer similarly to or better thar such as paste yield, $\mathrm{L}^{*}$ and $\mathrm{L}^{*} / \mathrm{C}^{*}$ values of the unsweetened paste, and $\mathrm{L}^{*}$ values of the sweetened paste. The large-seeded white beans such as 'Powderhorn' and 'Snowdon' showed the best potential for some of the paste traits. These commercial cultivars are currently used for other purposes such as canning, but they could also perform well as paste; therefore, if there is increased demand for bean paste in the United States or other parts of the world, it can be met with existing cultivars. Growing environments and/or the use of irrigation influenced the seed and paste qualities, so this should be an important consideration. With the promising genotypes and evaluation methods identified in this study, future experiments can be designed to evaluate and validate the per- formance of future bean cultivars and their suitability for paste production.

\section{Literature Cited}

Abramoff, M., P. Magalhaes, and S. Ram. 2004 Image processing with ImageJ. Biophoton. Intl. $11: 36-42$.

CIE International Commission on Illumination. 1978. Recommendations on Uniform Color Spaces, Color-Difference Equations, Psychometric Color Terms. Paris.

Desrochers, N. and P. Brauer. 2001. Legume promotion in counselling: An e-mail survey of dietitians. Can. J. Diet. Pract. Res. 62:193-198.

Dorrell, D.G. and M.W. Adams. 1969. Effect of some seed characteristics on mechanically induced seedcoat damage in navy beans (Phaseolus vulgaris L.). Agron. J. 61:672-673.

Hayat, I., A. Ahmad, T. Masud, A. Ahmed, and S Bashir. 2014. Nutritional and health perspectives of beans (Phaseolus vulgaris L.): An overview. Crit. Rev. Food Sci. Nutr. 54 580-592.

Kamiya, M., T. Takeuchi, and T. Kusume. 2004 Identification of a white common bean cultivar "Yukitebo" by DNA polymorphisms using PCR amplification [In Japanese]. Breed. Res. 6:29-32.

Kato, J. 2000. Studies on characteristics for food processing of Adzuki beans and common beans, and factors for their variation [English abstract]. Iwate University, PhD Diss.

Kelly, J.D. and K.A. Cichy. 2012. Dry bean breeding and production technologies, p. 23-54. In: M. Siddiq and M.A. Uebersax (eds.). Dry beans and pulses: Production, processing, and nutrition. Wiley-Blackwell Publishing Co., Oxford, UK.

Kelly, J.D., G.V. Varner, K.A. Cichy, and E.M. Wright. 2015. Registration of 'Alpena' navy bean. J. Plant Regist. 9:10-14.

Kelly, J.D., G.V. Varner, K.A. Cichy, and E.M. Wright. 2014. Registration of 'Powderhorn' great northern bean. J. Plant Regist. 8:1-4.

Kelly, J.D., G.V. Varner, K.A. Cichy, and E.M Wright. 2012. Registration of 'Snowdon' white kidney bean. J. Plant Regist. 6:238-242.

Kelly, J.D., G.V. Varner, S. Hooper, K.A. Cichy, and E.M. Wright. 2016. Registration of 'Samurai' otebo bean. J. Plant Regist. 10:109-114.

Kelly, J.D., G.V. Varner, B. Roman, and B. Long. 2009. Registration of 'Fuji' otebo bean. J. Plant Regist. 3:223-225.

Komiyama, S. 2013. The mechanism of darkening of Tebo Ann and a method for measuring color changes [In Japanese]. Summ. Res. outcome funded by Bean Promot. Progr. Grant 1-5.
Komiyama, S. and J. Kato. 2004. Evaluation method for texture (stickiness) of white bean paste made of common beans [English abstract]. Hokkaido Cent. Agr. Exp. Stn. Rep. 86:65-72.

Mendoza, F.A., J.D. Kelly, and K.A. Cichy. 2017. Automated prediction of sensory scores for color and appearance in canned black beans (Phaseolus vulgaris L.) using machine vision. Intl. J. Food Prop. 20:83-99.

Messina, V. 2014. Nutritional and health benefits of dried beans. Amer. J. Clin. Nutr. 100:437S$442 \mathrm{~S}$.

Miura, T., T. Narikawa, T. Ushirogi, and T. Inuzuka. 1977. New common bean variety "Hime-tebo" [English abstract]. Hokkaido Cent. Agr. Exp. Stn. Rep. 38:83-91.

Mkanda, A.V., A. Minnaar, and H.L. de Kock. 2007. Relating consumer preferences to sensory and physicochemical properties of dry 
beans (Phaseolus vulgaris). J. Sci. Food Agr. 87:2868-2879.

Ogle, D.H., P. Wheeler, and A. Dinno. 2019. FSA: Fisheries Stock Analysis. R package version $0.8 .24,<$ https://github.com/droglenc/FSA $>$.

Okuyama, M., S. Ebe, H. Sato, K. Mikami, K. Murata, H. Shimada, T. Ogawa, and M. Shimosaka. 2008. A new common bean variety "Kinu-tebo" [English abstract]. Hokkaido Cent. Agr. Exp. Stn. Rep. 92:13-27.

Ovando-Martínez, M., L.A. Bello-Pérez, K. Whitney, P. Osorio-Díaz, and S. Simsek. 2011. Starch characteristics of bean (Phaseolus vulgaris L.) grown in different localities. Carbohydr. Polym. 85:54-64.

Peterson, B., P. Carl, K. Boudt, R. Bennett, J. Ulrich, E. Zivot, and C. Dries, et al. 2019. R Package 'PerformanceAnalytics'. <https://pbil. univ-lyon1.fr/CRAN/web/packages/Perform anceAnalytics/PerformanceAnalytics.pdf>.

R Core Team. 2018. R: A language and environment for statistical computing. R Foundation for Statistical Computing, Vienna, Austria.
Rivera, A., D. Fenero, A. Almirall, J.J. Ferreira, J. Simó, M. Plans, R. Romero del Castillo, and F. Casañas. 2013. Variability in sensory attributes in common bean (Phaseolus vulgaris L.): A first survey in the Iberian secondary diversity center. Genet. Resources Crop Evol. 60:18851898.

Sadohara, R. 2020. Quality characteristics of bean paste as a confectionery ingredient and recent breeding efforts of common beans in Japan. J. Sci. Food Agr. 100(1):10-15.

Shinada, Y., S. Iida, I. Chiba, M. Hara, H. Sato, and M. Nakano. 1994. A new common bean variety "Yuki-tebo" [English abstract]. Hokkaido Cent. Agr. Exp. Stn. Rep. 66:25-34.

Shiota, Y. and Y. Miyata. 1976. Studies on "Ann" (bean jam) (part 4) [English abstract]. J. Home Econ. Japan 27:180-185.

Smith, D.K., L. Anne Riddle, S. Kerr, K. Atterberry, J. Lanigan, C. Miles, L.A. Riddle, S. Kerr, K. Atterberry, J. Lanigan, and C. Miles. 2016. Barriers and opportunities to serving pulses in school meals in Washington schools. J. Child Nutr. Mgt. 40(1):1-8.
Tazawa, A., H. Sato, H. Shinada, S. Aoyama, S. Fujita, K. Murata, I. Matsukawa, and N Hasegawa. 2015. A new Dinagon-brand Adzuki bean variety "Homare-dainagon" with soilborne disease resistance and high processing adaptability [English abstract]. Hokkaido Cent. Agr. Exp. Stn. Rep. 99:1-11.

Tyler, R., N. Wang, and J. Han. 2017. Composition, nutritional value, functionality, processing, and novel food uses of pulses and pulse ingredients. Cereal Chem. J. 94:1.

U.S. Department of Agriculture-Economic Research Service (USDA-ERS). 2017. U.S. per capita use of fresh and processing vegetables, dry pulse crops, and potatoes; cash receipts; U.S. vegetable trade.

Wu, D., and D.-W. Sun. 2013. Colour measurements by computer vision for food quality control - a review. Trends Food Sci. Technol 29:5-20.

Yam, K.L. and S.E. Papadakis. 2004. A simple digital imaging method for measuring and analyzing color of food surfaces. J. Food Eng. 61:137-142. 